\title{
Radio Broadcast and Indigenous Language Development in Nigeria: Contributions of the Radio Service of BRTV Maiduguri Toward the Promotion of Kanuri Language
}

\author{
Adamkolo Mohammed Ibrahim* \\ Lecturer, Department of Mass Communication, \\ University of Maiduguri, Borno State, Nigeria; \\ $\mathrm{PhD}$ student, Bayero University, Kano, Nigeria; \\ Lecturer and Coordinator, Mass Communication Diploma Programme, \\ Yobe State University, PMB 1144, KM 7 Gujba Road, Damaturu, Yobe State, Nigeria \\ Dorcas Rika Yake \\ Department of Mass Communication, University of Maiduguri, Borno State, Nigeria \\ Abubakar Sufyanu Saidu Al-Sadique \\ ${ }^{3} \mathrm{PhD}$ Research Candidate, Department of Mass Communication, \\ Bayero University, Kano, PMB 3011 Kano, Kano State, Nigeria; \\ Research Scholar, Department of Mass Communication, \\ The Federal Polytechnic, Bauchi, Bauchi State, Nigeria \\ Ahmed Lawal Gusau \\ Department of Mass Communication, Abdu Gusau Polytechnic, Talata Mafara, Zamfara State, Nigeria \\ Mohammed Nura Nguru \\ ${ }^{5}$ Lecturer, Mass Communication from the Information Unit, \\ Office of the Rector, the Federal Polytechnic, Damaturu, P.M.B.1006 Damaturu, Yobe State, Nigeria
}

The research was self-financed.

\section{Abstract}

Nigerian indigenous languages are facing challenges due to many factors including the ever-present long-term effects of colonialism and the use of English as the official language of communication and education, as well as urbanization, internal migration, and the mass media (both traditional and new). The preservation of indigenous languages has received global attention over the decades by notable international non-governmental organizations such as UNESCO and The British Council. In fact, the preservation of traditional cultural heritage, language inclusive, is one of the cardinal functions of mass media. Kanuri language, which is the main spoken language in Borno State in the northeast of Nigeria, is one of the several Nigerian indigenous languages facing challenges. Khaddamari, the headquarters of Jere Local Government Area, is a town very close to Maiduguri, a cosmopolitan city with population of about 1 million. Being so close to a large urban center it is known whether Kanuri language faces similar challenges it faces in the urban center, and if it does, what role does the media broadcasting from the city play toward promoting the language? This study examined the impacts of the Kanuri broadcast service of BRTV Radio, Maiduguri in the promotion and preservation of Kanuri language among the people living in Khaddamari town. Using the snowball sampling technique, 14 participants were recruited for indepth interviews from BRTV radio and Khaddamari town. The study found that BRTV's Kanuri broadcasts' contribution toward the promotion of Kanuri language at Khaddamari is progressively diminishing compared to how much it could have done so three decades ago and that some of the listeners were dissatisfied with several BRTV's Kanuri programs/news broadcasts. The study concluded that BRTV radio's contribution toward the promotion of Kanuri language in Khaddamari town is crucial but was minimal, often hampered by the dwindling broadcast power and reach of BRTV radio signals. Therefore, BRTV should address its infrastructural deficits and formulate articulate broadcast language policy.

Keywords: Radio broadcast and indigenous language, Radio program, BRTV Maiduguri, Indigenous language preservation, Kanuri language

DOI: $10.7176 / \mathrm{NMMC} / 99-01$

Publication date:October $31^{\text {st }} 2021$

\section{Introduction}

Local broadcast content in Nigeria is meant to be a conduit through which the people experience language and other cultures. However, nowadays, one of the indigenous cultural identities of the people of Khaddamari 
community in Jere LGA of Borno State is facing serious challenge. To be specific, Kanuri language, which is the main indigenous language of the people of the community is gradually giving way to other local languages such as Hausa. This problem is mostly observable among the younger people, who find it 'fashionable' not understanding and or speaking Kanuri language. In fact, it has come to the extent that some Kanuri youth would prefer to identify themselves with the 'borrowed' languages they speak in the street (e.g., Hausa) to their own mother tongue, Kanuri.

The magnitude of this problem may be understood better if we consider the fact that the younger generation may knowingly or unknowingly be helping toward the 'extinction' of one of the major indigenous languages in Nigeria and the main indigenous language in Borno State, which is Kanuri. Another considerable challenge bedeviling Kanuri language is lack of or dearth of literacy, meaning that there is serious lack of written texts in Kanuri language. Apparently, Kanuri is becoming one of the major 'spoken-only' languages in Nigeria despite its rich cultural heritage. For example, many literate (educated) Kanuri people do not and cannot write in Kanuri. Another example is, if you would take a ride or walk along the streets and roads of Maiduguri City, particularly Khaddamari community hardly will you see signboards and road signposts written in Kanuri language.

The researcher has observed that Kanuri language lessons taught in primary schools have been stopped for over three decades. For example, even postgraduate studies in linguistics in Kanuri may be hardly ever available the two universities located in Borno State (University of Maiduguri and Borno State University). However, ironically, for an individual to study linguistics in Kanuri, he or she must travel as far as Germany. Also, even in Maiduguri City, which is regarded as the 'capital' of Kanuri language in the world (Maina, 2016) Kanuri language is hardly ever used during formal occasions (except, for example, at royal palaces). All these problems could amount to posing an 'extinctive' challenge to the language.

Apart from everyday conversation, the only avenue presumed to possess the capability to promote Kanuri language is broadcasting (radio and television), especially the radio. For example, in the radio station under study there are programs and news broadcasts in Kanuri language. However, it is not known to what degree do these promote the use of the language; neither is the impact of these programs broadcast on the suitability of the language is known. Hence, the urge to carry out this study and close those knowledge gaps identified above to achieve the objective of the study, which is, to assess the commitment of the radio service of BRTV Maiduguri toward the promotion and preservation of Kanuri language at Khaddamari community, Jere Local Government Area, in Borno State, Nigeria.

This research work focused on the Kanuri broadcast service of the FM radio of Borno Radio State Television (BRTV) Maiduguri. Only people working in the programs and news departments of BRTV and all people in Khaddamari community who listen to radio were the potential participants of this study. The research becomes significant because it is one of the ways of exposing the Radio as a means of promoting Nigerians cultural heritage among youths. This research work is expected to serve as an eye opener for all categories of people to learn about their culture through the radio. The work is significant because it will explain in detail why people need to be conversant with their culture. In this research work, ways, and manners by which people can learn about their culture are identified and explained. Also, the relevance of Radio will be examined as a medium through which cultural knowledge and awareness can be acquired. Radio broadcast promotes cultural norms, values, and ethics just as it serves as a means of acquiring cultural education which will aid and promote societal decency.

\section{Literature Review}

\subsection{Role of Radio in the Promotion of Indigenous Cultures}

Since independence, radio broadcast programs have tried its best to live up to its objective of promoting cultural awareness throughout the Nigerian federation. Part of these objectives is to essentially cover the areas of aesthetics, religion, ethics, philosophy, language, history, and arts. In line with their objectives, radio programs have tried as much as possible to be oriented towards: (a) Seeking, identifying, and preserving Nigerian culture and promoting the study of Nigerian history and language. (b) Selecting critically, relevant foreign culture for the purpose of enriching Nigerian culture. (c) Developing and promoting the appreciation of indigenous aesthetic values by citizens. For example, one of the objectives of the Federal Radio Corporation of Nigeria (FRCN), formerly known as the Nigerian Broadcasting Corporation (NBC) is to "provide a professional and comprehensive coverage of Nigerian culture through broadcasting; to promote cultural growth through research into indigenous cultures, and to disseminate the results of such research" (Onabajo, 2000, p.14). The National Broadcasting Commission which was later set up by Decree 38 of 1992 as a regulating body for broadcasting in Nigeria was also given the duty of promoting Nigerian indigenous cultures, moral and community life through broadcasting.

The radio has been a very effective means of transmitting and promoting cultural, moral and community life most especially because of its unique characteristics. In most rural areas, the radio is the commonest mass medium that people can relate with intimately. It has been known as coming in handy anytime it is needed due to 
its easy mobility. Radio stations have therefore capitalized on this advantage to promote our cultural heritage. According to Moemeka (2000, p.120), radio can be used in cultural innovation or diffusion. Since culture is not static, radio could help remove the negative aspects of some of our cultures and help the citizens to absorb that, which will improve their welfare and culture awareness. It could also be used to bring to children, youths, and adults the greatest achievements of our cultural heritage in art, music, drama, poetry, language and so on.

\subsection{Mass Media and Indigenous Cultures}

By developing and promoting indigenous cultures rather than the current attrition and Westernization gestures of the mass media, these cultures would be transformed. First, the orientation of the media must change. The press must insist on at least a minimum standard of integrity, a minimum standard of decency from all 'Nigerians: our leaders in government, military, politics, media, commerce, business, professionals, traditional rulers and the citizenry (Allimi, 2005; Simon \& Ndoma, 2016). Allimi in Yusuff notes that cultural journalists must be the vanguard for portraying our good cultural values and societal norms to our children especially through relevant art, music, dance, drama, and sports. Let us use all the components of our art and culture to show that hard work and honesty pay (Allimi, 2005). Further, on the socialization role of the mass media, Moemeka writes as cited in Simon and Ndoma (2016) that the mass media help unify society and increase social cohesion by holding and teaching a broad base of common social norms, values, and collective experience. Through this activity, the mass media help transmit culture from generation to generation. Social norms, values and culture in general have become topics for conscious education by the mass media through the formal school system.

The mass media are also seen as playing the role of motivating and mobilizing people to attain their goals politically, socially, and economically as individuals and collective members of the society, which they do with some consideration of certain vital elements for sustainable national development (Chikaan, 2011). The mass media ought to promote and sustain indigenous cultures through publicity. But unfortunately, Nigerian mass media are yet to deliver significantly in this area. Belch and Belch describe publicity thus: publicity refers to non-personal communications regarding an organization, product, service, or idea not directly paid for or run under identified sponsorship. It usually comes in the form of a news story, editorial or announcement about an organization and/or its products and services. According to Maina (2016) in every culture, there are certain characteristics or traits which no matter how the culture changes, still remain very important. It is the role of the media to identify these aspects of the culture and emphasize them to the people, to preserve, maintain and uphold.

\subsection{Broadcast Media as a Tool for Promotion of Indigenous Cultures}

When the modern television broadcasting system came to Nigeria, the expectation was that it would provide adequate services in education, social and economic development. The system was also expected to transmit the Nigerian and African cultures, tradition, politics, literature, drama, and entertainment (Ugboaja, 1985). As expected, the system, at its inception, did very well in education. However, it left a big gap in cultural transmission. Between 1959, when television came to Nigeria, and 1975, the nation heavily depended on foreign imported programs. Ugboaja (1985) noted that only $25 \%$ of the programs were produced within the nation; the rest were foreign.

For this reason and because of the frequency allocation problem (Sobowale, 1983), the Federal Government of Nigeria decided in 1975 to take over the administration of all television stations in the country. While justifying the decision, the government said it would like to watch television 'highlight the way of life of Nigerians as against the present programs whereby foreign films which have no relevance to our way of life dominate their daily events' (Daily Times, 1975 November 10 cited in Ezaka, 2017). This intervention appeared to have changed the tide for good for cultural transmission and the use of local languages on the nation's television.

The radio system was also affected, as around this time, precisely in 1978, the Federal Radio Corporation of Nigeria (FRCN) Decree No. 8 was promulgated. According to Onabanjo (2005) maintained that amongst other things, it restructured FRCN into four linguistic zones, namely: Kaduna zone comprising with Hausa, Fulfulde, Kanuri, Nupe and English. Enugu zone also comprises Igbo, Tiv, Izon, Efik and English. Ibadan zone speaks Yoruba, Edo, Igala, Urhobo and English. Lagos zone comprising only English. The local languages and English designated for various zones became each zone's languages of broadcasting. Radio stations across the country contributed to the promotion of several Nigerian languages through various message types and programs: news, features, interviews, discussion programs and chit-chats. The situation has, however, changed with some radio stations and some languages in Nigeria. For instance,

Onabanjo (2005) further noted that the media in Cross River and Akwa Ibom States are no longer giving prominence to the local language known in that area as Efik. According to him, out of a total of 7560 minutes expended in broadcasting in the week, only a total of 425 minutes is allocated to the indigenous language, leaving a total of 7135 minutes for programs in English. This translates to 5.6\% for local language and $94.4 \%$ for English. The scholar stressed that the result is that the medium that should create awareness for the people in 
local language has little or no regard for the local language. Consequently, publishers' audience size dwindles and the attraction to publish in these languages became inexistent. The scholar also opined that the print media seem more culpable than the electronic media in the use of local languages. This is probably accounted for by virtue of the broadcast media being principally an oral/aural medium. Being oral, the indigenous language does not cost the broadcaster, who may not be able to write it, anything to broadcast in it. Also, being aural, it does not cost the listener, who may not be able to read the language, anything to listen to it. In other words, the broadcast medium breaks the barrier of illiteracy.

Since 1959, when the first Television station was established in Nigeria, which incidentally is the first in Africa, there has been a proliferation, of electronic media in the country (Onabanjo, 2000). The scholar further said that there are six geo-political zones in Nigeria, Zone A which is chosen for his analysis is in the Southwestern Nigeria and the dominant indigenous language spoken harp is Yoruba. Within a five-year period (1989-1993), the programs of two television Stations, 'NTA' owned by the Federal Government and Broadcasting Corporation of Oyo State (BCOS) owned by Oyo State Government, were analyzed. The method adopted is quantitative analysis which permits this researcher to find the proportion of media programs broadcast in Yoruba language, in English language and the proportion of imported programs. It is pertinent to mention that since 1970s the proportion of imported programs has drop sharply. Therefore, most of the programs in English language are locally produced (Onabanjo, 2000).

However, one key importance of the broadcast media is that they present programs in native languages. For instance, Federal Radio Corporation of Nigeria (FRCN) relayed programs in Hausa, Yoruba, and Igbo to educate their listeners on issues of public interest and events as it unfolds within their domains. Another example is BRTV presents programs and news in Kanuri language (which is dominant language in Borno State) and other minor languages such as Shuwa Arab, Fulfulde, Babur Burah and Marghi. Many of such programs are those ones that encouraged parents to educate or teach their children their native languages.

In line with the indigenization concept, indigenous language programme is a catalyst in strengthening the concept of becoming oneself, especially as it concerns the recognition of the importance of self, getting to know and accept self. They are vital treasure of the autochthonous people, who use them as a language of love and intimacy and as a vehicle of thought to express ideas, sentiments, felling and values among one another (Ezaka, 2017). The thin line between language and culture underscores the significance of indigenous language in communication.

Katz and Wendell (1998) posit that in all multi-national countries' broadcasters struggle with the dilemma caused by linguistic diversity. They recognized that broadcast in local languages is a good means of mobilizing participation in socio-economic development. Language in this respect is regarded as an important instrument and vehicle of Communication. Therefore, using the local dialect to communicate to the people enhance participation in various socio-economic development programs. Baran (2002) supports this assertion by saying that more than anything else, it is through language that an individual becomes a member of his social community and through which he becomes acculturated into his community. Baran says that since most nonliterate people receive a great deal of their information by word of months rather than by reading, radio takes advantage of the listeners. This means that radio and television are the most appropriate medium that can transmit messages in the local language.

Similarly, also Kunczik (1984) asserts that media such as radio and television can contribute to the identity and continuity of national cultures by giving expression to their indigenous arts. Also, Wimmer and Dominic (1987) notes that the media are expected to respect if not support the dominant values of their own society and of their own national society. Isa (2005) believes that the media have responsibility of helping the people to preserve their cultural values and arts, which include dance, music, folktales etc. through the programs they transmit to the public. Thus, Isa states that the main function of social mobilization is to inform communities about development programs for the purpose of increasing, awareness, the information should motivate the community to think and ultimately act. One way to reach the community with social mobilization programme is using Broadcast media, especially the Radio.

\subsection{Theoretical Framework}

\subsubsection{The Cultural Norms Theory}

McLuhan introduced this theory in 1964. The theory assumes that people tend to shape their lives according to the dominant way in which the media presents selected issues. According to Isa (2005), some subjects were emphasized or portrayed on purpose to influence people due to the style of their presentation. Thus, through selective presentation and "hype" about certain "themes", the radio creates an idea among the audience that such topics are part of society, or are cultural norms given to society. The "socially influenced" members of society often follow such media presentations (Mojekeh et al., 2019).

Meanwhile, critics assert that the media are likely, if not vetted, to emphasize bad behaviour and mislead people, yet the media can also encourage good behaviour at the same time. Thus, cultural norms theory provides 
the much-needed theoretical understanding regarding the investigation of the role of radio in spreading and sustenance of cultures and languages. For example, the more the radio focuses on the importance of culture, the more people tend to follow it and plan their lives towards it. In other words, what the radio says or broadcasts about culture is what can make a community a much better place to live (Mojekeh et al., 2019).

2.4.2 The Social Responsibility Theory of the Press

The theory of social responsibility was first developed in the 1940s by Robert Maynard Hutchins. To combat pressures threatening press freedom, this theory was first introduced in 1947 and recommended by the Hutchins Commission on Freedom of the Press. It states that the media must serve the public, and to do so, they must remain free from government interference. It sets out guidelines that the media must follow to fulfil their obligation to serve the public (Ezaka, 2017; Issa, 2005). The theory claims that media can be self-regulating by adhering to the following principles: (1) the media have to fulfil towards a democratic society to preserve freedom; (2) the media should be self-regulated; (3) the media must have high standards of professionalism, objectivity, truth and accuracy; (4) the media should reflect the diversity of the cultures they represent; and (5) the public has the right to expect professional performance.

\section{Methods}

\subsection{Research Design, Sample and Sampling Technique}

This study adopted a semi-structured qualitative survey approach. Specifically, the in-depth interview approach was adopted (Nieuwenhuis, 2007). From both the BRTV radio and Khaddamari community a total of 12 participants were interviewed between October 2 and 16, 2019. From the BRTV radio, only two broadcast personnel (one from programmes department and the other from news and current affairs department) were interviewed while from Khaddamari community, 10 participants who listened to the BRTV radio Kanuri programmes and news were interviewed. Due to the research design adopted and the nature of the study, snowball sampling was employed (see Van Dijk, 1993).

\subsection{The Instrument for Data Collection and Method of Data Analysis}

The data were gathered using in-depth interviews. At the BRTV radio, two interviewed were conducted using an eight-item question guide while at Khaddamari community, 12 interviews were conducted using a 12-item question guide. Both versions of the question guides contained both closed-ended and open-ended questions, with most of the questions being open-ended. The question guide was designed based on the theoretical framework of this study, i.e., the Social Responsibility Media Theory and Cultural Norm Theory. The interviews were semi-structured to elicit in-depth responses to the research questions from the participants. All the interview data were collected in audio format and analysed using the Critical Discourse Analysis (CDA) approach based on Van Dijk’s (1993) recommendation.

\subsection{Location of the Study}

Khaddamari community was chosen for this study because of its semi-urban nature despite its proximity to Maiduguri metropolis and because BRTV radio's signals are well received there. Khaddamari is the headquarters of Jere LGA, one of the 27 LGAs of Borno State. It is situated at about $25 \mathrm{~km}$ from Maiduguri city centre and located between latitudes $11^{\circ} 40^{\prime \prime}$ and $12^{\circ} 05^{\prime \prime} \mathrm{N}$ as well as longitudes $13^{\circ} 50^{\prime \prime}$ and $12^{\circ} 20^{\prime \prime}$ E. It occupies a landmass of $169 \mathrm{~km}^{2}$ and has a population of 211,204 with an annual growth rate of $2.8 \%$ (according to NPC, 2006). Most of the settled farmers are of the Kanuri ethnic group while pastoralists in the area are mostly Shuwa-Arab, Fulani, Bodai, Koyam and Buduma. These ethnic groups are largely semi-settled pastoralist practising some form of arable farming while the greater number of their herds is with their nomadic tribesmen. Also, nomadic Fulani pastoralists known as Bokoloji and Udaa who seasonally come to the area from neighbouring countries of Niger and Chad Republics in search of water and pasture can be found there.

\section{Data Presentation and Analysis}

\subsection{BRTV Radio's Operational Role in Indigenous Language Preservation}

The researchers sought to know the reason why the BRTV radio broadcasts news and programmes in Kanuri despite English being the official language of broadcasting in government-owned broadcasting stations in Nigeria. Given this, a participant, Ali Mamman Shuwa says,

$B R T V$ is the only radio station operating with a very high frequency (VHF) and ultra-high frequency (UHF). Majority of the radio and television stations in Nigeria only operate under the license of UHF but in the cast of BRTV, it is operating on VHF because Borno is the only state in the federation that borders with three neighbouring countries of Chad, Niger and Cameroon.

Historically, the Kanem Borno Empire has Kanuri speakers in different countries down to Yemen to Libya. During those days, people use to go for trading from Nigeria to Ghana, Sudan down to Yemen and so forth. The only means of communication was the radio signals that is why the Borno radio is used to Broadcasting in 
Kanuri language both news and some of its awareness programmes. This view is not too different from that of Isa Adamu, who posits that "Kanuri are the predominant people in the state and only broadcasting in Kanuri can ensure that majority of the people are carried along."

Borno is a large state with several ethnic groups such as Kanuri, Shuwa Arab, Babur Burah, Fulani, Marghi, etc. radio being the cheapest medium of mass communication is often established to serve the masses. However, there are various political interests in this state. Probably the Kanuri service of the BRTV radio was established for the government and the management of BRTV Maiduguri to achieve some political interests rather than for the preservation of indigenous languages in the state. According to Ali Mamman Shuwa, BRTV does not transmit in Kanuri language alone; it broadcasts in about 14 different local languages. For news, it broadcasts in English, Kanuri, Hausa, Babur Bura, Fulfulde, Marghi and Shuwa Arab in addition to programmes broadcast in other languages like Waha and Guduf of Gwoza and Kanakuru of Shani LGAs. Furthermore, Marghi has half an hour with Paul Sikari in Marghi, the Alwajib-as-Salim in Shuwa Arab and the Sakan Mburci in Babur Burah and so on. The participant stressed that politics was not part of the initial reason the station was created, rather promote the cultural heritage of the people. Corroborating, Ali Adam said that the population of Kanuri speaking people is up to $70 \%$ of the LGAs in Borno. So, Kanuri language becomes essential when it comes to politics to pass messages across most of the people in the state.

Reflecting on the historical perspective of BRTV Maiduguri, Participant B1 states that BRTV radio started as short wave (SW) broadcaster, after some years it went off; then medium wave (MW), after some years it went off and currently FM. This makes us exercise fears about the future of BRTV and Kanuri language news and programmes in particular.

So, the researchers sought to know the future of the BRTV radio service and Kanuri language news and programmes considering the changes the station has been undergoing. To Participant B2, it is advancement in technology that result in such changes. Right now, the station is on streaming so that with your android phone you can switch on to BRTV News 24 and listen to all the programmes and news for the whole day or the past one months. The Borno State government has provided enabling environment such that right now, the station has about $220 \mathrm{KW}$ transmitters of frequency modulated (FM) and that of the medium wave (MW) transmitters of 240 kilowatts which are about to be commissioned where the signal is going to be received worldwide in addition to the technological advancement of the modern ways of broadcasting using internet transmission.

Participant B1 shares a similar opinion but with a slight variation:

...there is no need for panic over the transmitter being used. Presently, we are having 250KW that can transmit beyond even Nigeria. Gone are the days of short-wave Medium, i.e., when Federal Radio Corporation of Nigeria left to BRTV. As the transmitters went faulty, new ones were installed.

This implies that the future of BRTV is bright and even brighter with the support of the Prof. Babagana Zulum Government. However, with the current realities in BRTV - limited reach (probably not more than 50km radius, which ultimately means limited audience), limited local language broadcast hours per week, etc., arguably, the BRTV radio service has limited commitment toward the preservation of Kanuri language. Participant B2 explains that,

With the commissioning of the 20 kilowatts transmitter at the FM, the short-wave radio transmission has become a thing of the past.... Currently, people from the Niger Republic are receiving the signals, people from Jigawa, up to Plateau State, to Bauchi and some areas of Gombe. Though going by the NBC code transmission, Stations are only allowed to transmit Metros Sound alone, but because of the insurgency the Commission understands with BRTV station and overlooked this problem because the radio signal is essential in tackling security situation in the country.

Participants B3 explains the predicament of BRTV as follows.

We have not limited our services. What is happening is that the transmitter we are using now is 1 kilowatt, but it goes beyond 50km. FM is meant for within a certain area, but the short wave (SW) is what makes it far. I don't believe that audience beyond $50 \mathrm{~km}$ will not get it.

This implies that although the FM broadcasting service is meant for short-range, the defunct short-wave service made BRTV to be heard in faraway places. However, it is not known if the management of BRTV regards the preservation of local languages and cultures especially Kanuri language as a social responsibility or mandatory. Participant B1 notes,

...the management of BRTV has regarded the preservation of local language as mandatory. The management doesn't take it lightly mostly on anything that happens, especially news because the primary responsibility of the station is news after which other things are secondary. The management deems it necessary that all the news content including that of the Kanuri language must go on air as and when due. 
The participant went further to say that the management of BRTV promotes six or more indigenous languages which include Hausa, Shuwa Arab, Babur Burah, Fulfulde, Kanuri, Marghi among others, adding that,

When it comes to the programme of the whole languages in Borno State, we have a programme for

those tribes here. We have more than 10 languages now going on here. Hence, the management did not limit services to the Kanuri alone.

This indicates that management of BRTV promotes not only Kanuri language but also other indigenous languages like Hausa, Shuwa Arab, Babur Burah, Fulfulde, Kanuri and Marghi, among others. Further, the researchers sought to know the hours allocated to Kanuri news/programmes per week on the BRTV radio. Participant B1 explains that much is allocated to Kanuri news during the five daily news bulletins of BRTV: 10 minutes at $6: 30 \mathrm{am} ; 5$ minutes for News Summary during noon; 10 minutes by 5 pm; another 5 minutes by 8 pm; and another 5 minutes by $10 \mathrm{pm}$.

The researchers went further to ask the participants if the daily airtime allocated to Kanuri news mentioned previously is enough to promote and preserve Kanuri language in the state and whether there were any possibilities of increasing the number of daily broadcast hours. Ali, participant B1 stresses that "the hours are not enough to promote Kanuri language, because news is supposed to be hourly so that people will know what is happening in their environment." However, the participant was not sure if there were possibilities of increasing the numbers of hours, saying, "it will need a lot of resources to reach to such level and the area is too diverse. You inject 10 million Naira today, tomorrow you need another additional 20 million Naira. The running cost matters". This implies that despite the airtime allocated to Kanuri news might not be enough to warrant its preservation, no possibilities of the increase of airtime any time soon.

\subsection{BRTV Radio's Role in Kanuri Language Preservation at Khaddamari}

Most of the participants at Khaddamari appreciated the quality of the BRTV radio Kanuri news and programmes broadcast because the BRTV radio signals are received clearly in Khaddamari. However, some of them pointed out some grey areas such as they hardly receive the signals of the FM broadcaster of BRTV and that Kanuri programmes seemed to be confusing because of the misuse of vocabularies by presenters and newscasters, for example, the expression Komishina Korkorye instead of Komishina K3ndaramye (meaning the Commissioner of Environment).

Most of the participants listened to Kanuri news and programmes of the BRTV radio anytime they are by their radio sets, especially during news bulletin hours say around $5 \mathrm{am}, 12$ noon and $8 \mathrm{pm}$. However, Participant K3 points out that "due to the misuse of terms in most of the news broadcasts, I don't listen to it except when seasoned broadcasters such as Ahmed Shettima are casting the news." Moreover, many of the participants indicated that Kanuri is their identity, culture, and life; and it is so dear to them because it is the language of communication, the means of doing business and the major language in the town of Maiduguri. Others claimed that listening to the Kanuri Programmes usually enriches their Kanuri vocabularies and that it goes a long way in explaining to the people the happenings of government and their community.

"BRTV programmes have helped promote and uphold Kanuri traditions and cultures," says Participant K9 "as many forgotten vocabularies, expressions and even cultures are brought to light", while others regarded the BRTV radio as lagging in modern technology and innovation. For instance, in Hausa broadcast on the international broadcast stations like the Hausa services of the BBC, VOA, DW Radio and RFI, Participant K2 laments that "new words and terms are coined by seasoned broadcasters and are generally accepted and used by the people, for example, a missile in Hausa is called makaami mai linzami but there is no Kanuri word for such stuff."

Most of the participants said that radio has been broadcasting in Kanuri in Borno State for many, many years. News and programmes in Kanuri language including Kanuri traditional music, Islamic religious poems in Kanuri, Kanuri drama and Kanuri requests or greetings are presented daily on the BRTV radio service; and that all these have a big impact on Kanuri people at Khaddamari community. As a matter of fact, according to Participant K5, "living in a society without a radio is unimaginable", considering the role played by radio mostly in updating the younger generation on Kanuri culture and traditions in this globalized world. The participant went further to say that,

some important aspects of the Kanuri programme are missing, for instance, 'Nzuri Bultuye' drama has gone together with the talents; most of the classic traditional Kanuri musicians have passed away and no one seems to be interested in taking over their career among the younger generation. Hence, the need for Borno State government to invest in the Ministry of Information and Culture through the radio service to sprang new generations of Kanuri singers and artists.

However, Participant K 1 notes that the problem of listening to Kanuri radio programmes and news at Khaddamari is that "majority of the people living here are Shuwa Arab and there is a little antagonism broadcasting to them in Kanuri. BRTV should increase the airtime allocated to and quantity of programmes in Shuwa Arab language." 
Because of the influences of modern times and modern technologies, many aspects of Kanuri cultures and language such as vocabularies and the real Kanuri accent may be getting lost especially among the younger generations at Khaddamari. BRTV radio can play a significant role in the preservation of Kanuri culture and tradition. Participant K2 notes,

Before there used to be important programmes like 'Nzuri Bultuye', 'Bintu'a Dala'a' and others, which helped in promoting Kanuri culture and vocabulary but for over 20 years this has stopped. For now, programmes sustaining Kanuri culture [better] are the Islamic preachers who preach Islam in Kanuri language and because they mastered the language, this is making BRTV popular and reliable.

Favourite programmes for most of the participants include Salamma and Kanem Gai (in Shuwa Arab), Liwuram (in Kanuri), news broadcast (particularly by Ahmed Shettima) and the request (greetings) programme in Kanuri which, according to Participant K1, "people even spend money on such programmes just to send 'onair' greetings and shout outs to their friends, loved ones, neighbours, business associates and so on." The participant further indicated that the BRTV radio contributes toward the preservation of Kanuri cultures and language by highlighting the forgotten aspects of the culture as well as encouraging listeners to adhere to original Kanuri culture. Moreover, Participant K4 claims that "about $90 \%$ of BRTV programmes are in Kanuri, thus, other local languages could be marginalized." However, most of them agreed that the BRTV radio promotes cultural and religious practices such as marriage, circumcision, domestic life, Ramadan Tafseer, Eid el-Kabir and Eid el-Adha and folk music such as ganga-kura, gunda, bankaura, dunu, shila-shila, among others.

Some of the participants believed that missing Kanuri news and programmes means a lot to them as Participant K10 says, "Whenever I missed Kanuri news or cultural programmes, I feel as though I lost money". Others, however, did not feel losing anything if they missed a Kanuri programme or news because these are frequently repeated. Participant K9 says, “... if I were to rate them, I will give BRTV less than 25 out of 100. ." Furthermore, most of the participants showed dissatisfaction with the obsolete method of broadcasting, the wrongful translation of Kanuri language and the importation of Hausa or English words into the Kanuri language during programmes. Participant K7 laments that "the late commencement of the programme is a serious issue, which, if the news caster is not around that is the end of the news; this is more common with the Hausa news broadcast." Another key problem most of the participants highlighted is frequent power outage.

\section{Conclusion and Recommendations}

BRTV has been instrumental in promoting the Kanuri culture and tradition, considering the numbers of programmes being aired in Kanuri and the distance covered by the transmission. Notwithstanding, the flaws in terms of wrongful interpretation of words and the obsolete way of communication. Listeners still enjoy listening to the programmes/news especially Salamma, Kanem gai, Liwuram. The findings of this study affirm the assertion that stronger indigenous languages contribute to the extinction of other smaller indigenous languages (Lambu, 2020). Some of the participants believed that Hausa language is a threat to the existence of Kanuri language same way as the Kanuri language threatens the existence of other minor local languages like the Shuwa, Babur Brah, Marghi, Gwoza among others. Hence, the need for BRTV to, as a matter of social responsivity and cultural norms preservation, focus on the preservation of Kanuri language. Therefore, this study concludes that the radio service of the BRTV radio has impacted positively on the preservation of Kanuri language among people of Khaddamari town in Jere LGA of Borno State. Despite having most of its programmes broadcast in Kanuri language, the degree of its impacts on the preservation of Kanuri language at Khaddamari town not much as expected. Some of the impediments identified include the lack of effective broadcast language policy, weakening broadcast power (signals) and other infrastructural and skilful and professional workforce deficits, which are often politically attributed to the lack of modern, powerful transmitter, medium wave (MW) and/or short wave (SW) that can enable the station's programmes to be listened to in the entire state. Also, the social responsibility theory of the press and the cultural norms theory are still valid to explain research problems like these in a setting like this one.

This study recommends that future study should use a quantitative approach to investigate this problem in the entire state, not only limited to Jere LGA. The government should leverage resources for the procurement and installation of a powerful transmitter capable of covering the entire state. The Borno State Government should consider overhauling BRTV in its entirety in terms of structure, technology, workforce, and operation to restore its lost golden glory. There is need for Kanuri broadcast to go online. So that people can access and reaccessed the contents of BRTV programmes/news whenever the need arose.

\section{References}

Adéníyì, H. \& Béllò, R. (2006). Nigerian media, indigenous languages and sustainable development. In O. F. Arasanyin \& M. A. Pemberton (Eds.), Selected proceedings of the 36th annual conference on African linguistics (pp. 155-160). Cascadilla Proceedings Project. 
Allimi, T. (2005). Cultural journalism in Nigeria. In J. B. Yusuff (Ed.), Culture and the media in Nigeria. Abuja: National Institute for Cultural Orientation.

Baran, J. (2002) Introduction to mass communication media literacy and Culture. Boston: McGraw Hill.

Chikaan, G. J. \& Ahmad, I. J. (2011). Mass communication for beginners. Makurdi: Azaben Publishers.

Emeka-Nwobia, N. (2015). The place of indigenous Nigerian languages in national development. Research in Humanities and Social Sciences, 5(12), 112-116.

Etika, D. N. \& Edwin, E. A. (2018). Broadcast media as tools for promotion of indigenous languages in Nigeria: A study of Hit FM Calabar. International Journal on Transformations of Media, Journalism and Mass Communication, 3(1), 32-43.

Ezaka, S. (2017). Radio programming in indigenous language and rural development in south eastern Nigeria. World Applied Science Journal, 35(5), 822-835.

Isa, M. (2005). Culture and the media: An overview. In J. B. Yusuff (Ed.), Culture and the media in Nigeria. Abuja: National Institute for Cultural Orientation.

Katz, E. and Wedell G. (1978) Broadcasting in the third world. London: Macmillan Press Limited.

Lambu, B. (2020). Hausanisation of Nigerian cultures. In S. Brunn \& R. Kehrein (Eds.), Handbook of the challenging world language map (pp. 1145-1153). Springer, Cham. doi: 10.1007/978-3-030-02438-3 53

Maina, F. A. (2016). The impact of Kanuri language on performance and retention of basic science and technology concepts among pupils in Maiduguri Metropolis, Nigeria, (unpublished master's dissertation), Ahmadu Bello University, Zaria, Nigeria.

Moemeka, A. (2000). Development communication in action: Building understandings and creating participation. Lanlian, Maryland: University Press of America Inc.

Mojekeh, M. O., Egbeh, P. C., Nwangene, O. \& Dim, N. O. (2019). Radio listenership-base influences and audience perception of radio stations in Owerri, Nigeria. Contemporary Marketing Research Journal, 6(2), $1-10$.

Nieuwenhuis, J. (2007). Introducing qualitative research. Sage Publications.

Olabode, E. A. (2019). Indigenous languages in Nigeria: Problems and prospects. Erudite Journal, 1(1), 104-111.

Onabanjo, F. (2005). Promoting indigenous culture and community life in Nigeria through the mass media. Studies in Tribes and Tribals, 3(2), 93-98.

Onabajo, O. (2000). Fundamentals of broadcast journalism. Lagos: Gabi Concept Ltd.

Simon, R. O. \& Ndoma, B. E. (2016). Nigerian media and indigenous cultures transformation: The journey so far. Journal of Mass Communication and Journalism, 6(3), 1-7. doi: 10.4172/2165-7912.1000317

Sobowale, I. (1983). Scientific journalism. Lagos: John West Publication.

Ugboaja, F. (1985). Ora media in Africa. In F. Uaboaja, (Ed.), Mass communication, culture and society in West Africa. Munchem: Hanszell.

Van Dijk, T. A. (1993). Principles of critical discourse analysis. Discourse and Society, 4(2), 249-283. doi: $10.1177 / 0957926593004002006$

Wimmer, R. D. \& Dominick, J. R. (1987). Mass media research: An introduction. Boston: Wadsworth Inc. 